\title{
IONOSPHERIC DISTURBANCES BEFORE AND AFTER THE JANUARY 14, 2018 EARTHQUAKE IN PERU
}

\author{
Carlos SOTOMAYOR-BELTRAN
}

Imaging Processing Research Laboratory (INTI-Lab), Universidad de Ciencias y Humanidades, Av. Universitaria 5175, Los Olivos, Lima, Peru

*Corresponding author's e-mail: csotomayor@uch.edu.pe

\begin{tabular}{l} 
ARTICLE INFO \\
\hline Article history: \\
Received 29 September 2018 \\
Accepted 27 December 2018 \\
Available online 9 January 2019 \\
\hline
\end{tabular}

\section{Keywords:}

Ionospheric disturbances

Vertical Total Electron Content Earthquakes

Equatorial Ionization Anomaly

\begin{abstract}
An earthquake of Mw 7.1 occurred on January 14, 2018 in the southern coast of Peru. In this study, public available Global Ionospheric Maps (GIMs) provided by the Center for Orbit Determination in Europe (CODE) were used to look for ionospheric disturbances pre- and postearthquake. Twelve days before the seismic event, a positive anomaly was detected at low latitudes in the northern hemisphere in differential vertical total electron content maps. Moreover, given the low-latitude nature of this incident, changes in the shape of the Equatorial Ionization Anomaly (EIA) were analyzed as well. A significant amplification of the northern crest in the EIA of $33.3 \%$ was also observed 12 days before the earthquake. Because the geomagnetic and solar conditions for January 2, 2018 were very quiet and also knowing that natural ground radioactivity produced by the earthquake's preparation can increase the total electron density in the EIA, it is considered that this ionospheric disturbance is product of the earthquake's preparation. Additionally, the detection of a negative ionospheric anomaly 2 days after the incident is reported. An association to the earthquake of this negative disturbance is hinted at, due to the also the rather quiet geomagnetic and solar conditions after the seismic occurrence.
\end{abstract}

\section{INTRODUCTION}

Earthquakes, depending on their magnitude, can not only cause a lot of infrastructure damage but also be responsible for the lost of many human lives. In order to provide efforts on the search of earthquake's precursors many past studies have analyzed ionospheric anomalies before the occurrence of seismic events. Some of these studies (e.g., Zakharenkova et al., 2006; Zakharenkova et al., 2008; Mubarak et al., 2009; Zhu et al., 2010; Zou and Zhao, 2010; Yao et al., 2012; Zhu et al., 2013; Xinzhi et al., 2014; Guo et al., 2015; Li et al., 2015; Pundhir et al., 2015; Alcay, 2016; Sharma et al., 2017; Akhoondzadeh et al., 2018; Sotomayor-Beltran, 2019) have confirmed the presence of ionospheric variations days before the occurrence of an earthquake. On the other hand, only a few studies (e.g., Zou, 2010; Xinzhi et al., 2014) have reported ionospheric anomalies a few days after an earthquake. Evidently, ionospheric disturbances may also arise due to some other natural phenomena or even man-made causes (Afraimovich et al., 2013); for instance, due to geomagnetic storms (Buonsanto, 1999; Danilov, 2013). Hence, the aforementioned studies on seismo-ionospheric signatures, ruled out any influence of such disturbances for their analyses.

Making use of Global Ionosphere Maps (GIMs), which are maps at a global scale of the vertical total electron content (VTEC), Pundhir et al. (2015) detected ionospheric disturbances 5-7 days before the seismic event in Agra, India. They detected these by simply looking into the diurnal variations of the VTEC right over the epicenter. In a similar fashion, Mubarak et al. (2009) pointed to variations a few days before in the VTEC over the earthquake's location in Simeulue, Indonesia. Li et al. (2015) and Zhu et al. (2010) detected an anomaly in the ionosphere over the location of the epicenter 3 days prior to the occurrence in Wenchuan, China. However in these studies, they did not look into the line of sight above the epicenter, but produced two-dimensional ionospheric anomaly maps based on GIMs. The reliability of GIMs as indicator of space weather activity has been pointed out by Coster and Komjathy (2008) and HernándezPajares et al. (2009). Zhu et al. (2013) detected an ionospheric anomaly 6 days before a seismic event that happened near Sumatra, Indonesia. This observation was possible once again by looking into differential ionospheric maps. In another unrelated incident in Sumatra, Indonesia, Zakharenkova et al. (2006) saw variations in the ionosphere days before this new seismic event. In this case, they noticed these variations by looking into changes of the shape of the Equatorial Ionization Anomaly (EIA). Generating global ionospheric disturbance maps, Xinzhi et al. (2014) observed a strong positive disturbance 12 days before the earthquake in Yutian, China. They also detected 2 days after the seismic event a negative 


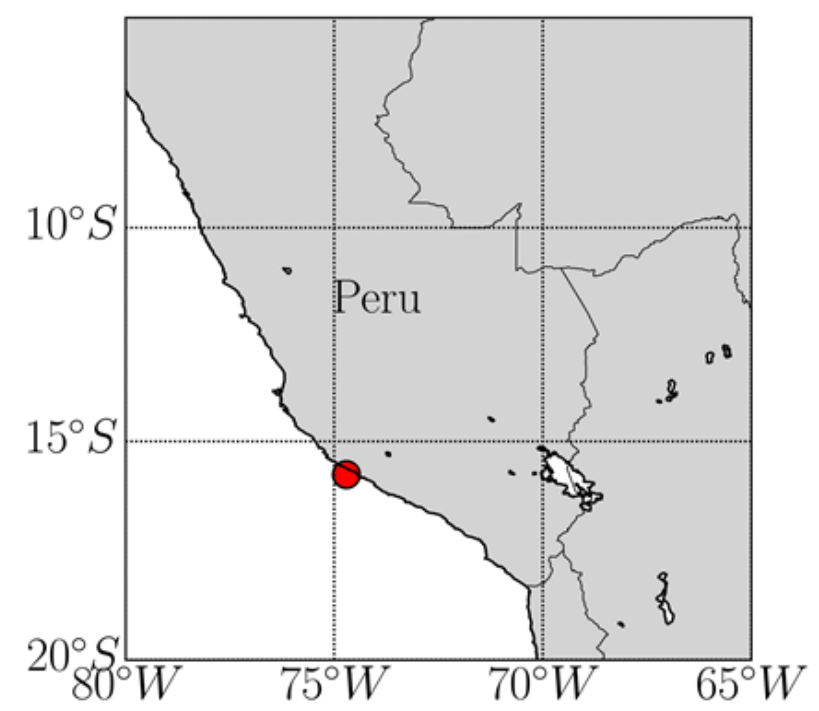

Fig. 1 The epicenter of the Acari earthquake is indicated by the red circle.

anomaly. Similarly to Xinzhi et al. (2014), Zou and Zhao (2010) have also detected an ionospheric disturbance 8 days after the earthquake that happened in Peru in the year 2007.

In this paper, the appearance of ionospheric anomalies some days before and after the catastrophic earthquake that happened on January 14, 2018 in Peru are presented.

\section{THE ACARI EARTHQUAKE}

At the beginning of the year 2018, on January 14, at 09:18 UT (04:18 local time; LT), a major earthquake of moment magnitude (Mw) 7.1 struck off the southern coast of Peru, near the town of Acari. As shown in Figure 1, the epicenter was located at $15.77^{\circ} \mathrm{S}$ and $74.71^{\circ} \mathrm{W}$. According to the United States Geological Survey (USGS) this seismic event occurred at a depth of $39 \mathrm{~km}$. The Acari earthquake is the result of the Nazca plate subduction process beneath the South American plate. As reported by the media, the aftermath of this incident caused the lost of two human lives, several persons injured and many houses of mud brick material and roads were badly damaged.

\section{METHODOLOGY}

\subsection{IONOSPHERIC DATA}

GIMs are provided in the form of IONosphere map EXchange (IONEX) format files (Schaer et al., 1998). These files are provided by centers like the Center for Orbit Determination in Europe (CODE) or by the Crustal Dynamics Data Information System (CDDIS). For the analysis of the ionosphere before and after the earthquake, data from CODE, which are derived from about 300 GPS sites of the International Global Navigation Satellite System Service (IGS) and other institutions, were used.

VTEC maps from CODE are provided in a geographical grid, the resolution in longitude is of $5^{\circ}$ and in latitude of $2.5^{\circ}$. These maps are built under the consideration that the ionosphere can be modeled as a thin spherical shell that surrounds the Earth at a determined height $(h=450 \mathrm{~km})$. GIMs are produced every hour. The VTEC values are given in TEC Units (TECU), where $1 \mathrm{TECU}=10^{16}$ electrons $/ \mathrm{m}^{2}$.

IONEX files where retrieved from CODE via ftp (ftp.aiub.unibe.ch/CODE/) starting 15 days before (December 30, 2017) the seismic event until 10 days (January 24, 2018) afterwards. Due to the structure of the IONEX files, which consist of header and data (the VTEC data themselves) parts, a program in Python to split these two parts had to be written. Afterwards, using the NumPy library from Python (which allows to relatively easily handle N-dimensional arrays), the VTEC values were arranged into 3D cubes for further analysis. The $x$ and $y$ axes of the cubes are the longitude and latitude, respectively, and the $z$ axis is the number of GIMs.

\subsection{GEOMAGNETIC AND SOLAR CONDITIONS}

In order to rule out any influence from geomagnetic and solar activity, the behavior of three very important indices were assessed.

The Dst index monitors the level of intensity of geomagnetic storms. For Dst $>-20$ nT the geomagnetic activity is considered quiet and for $-20 \mathrm{nT} \geq$ Dst $>-50 \mathrm{nT}$ the magnetic storms are considered of small intensity. If $-50 \mathrm{nT} \geq$ Dst $>$ $-100 \mathrm{nT}$ the storms are of medium intensity. Finally, if $-200 \mathrm{nT}<$ Dst $\leq-100 \mathrm{nT}$ and Dst $\leq-200 \mathrm{nT}$, the storms are considered of large and severe intensity (Xinzhi et al., 2014), respectively . Dst index data from the World Data Center for Geomagnetism in Kyoto (http://wdc.kugi.kyoto-u.ac.jp/wde/Sec3.html) for the months of December 2017 and January 2018 were retrieved. In Figure 2 it can be seen that for the range of days selected there are no major magnetic storms.

The Kp index measures the disturbance of the horizontal component of the geomagnetic field. Data for this index were obtained from the German Research Centre for Geosciences (GFZ; 


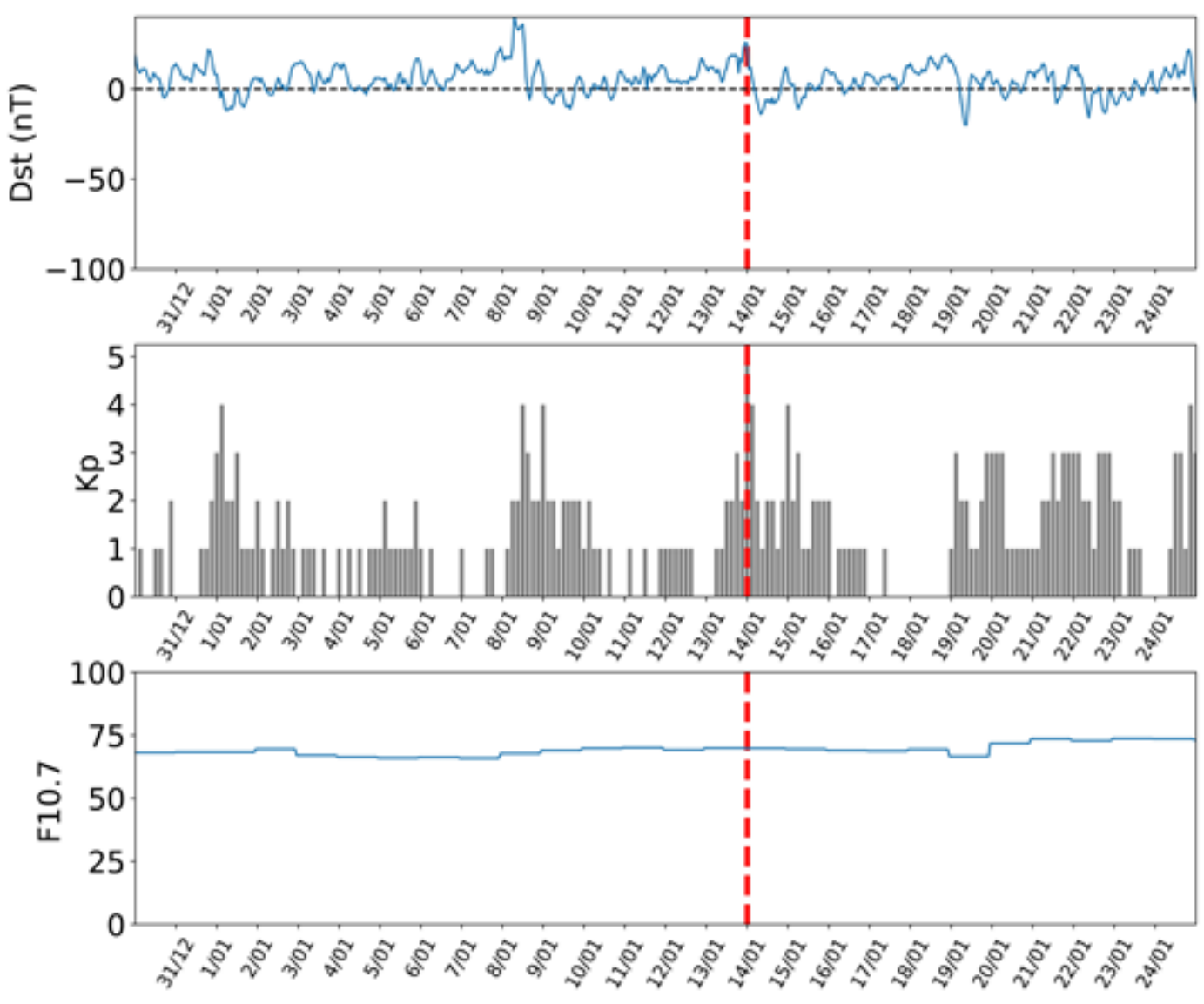

Fig. 2 Dst, Kp and F10.7 indices for the period between December 30, 2017 and January 24, 2018. The red dashed vertical line indicates the day the earthquake happened.

https://www.gfz-potsdam.de/en/kp-index/) also for the months of December 2017 and January 2018. Figure 2 shows that for the range of selected days, $\mathrm{Kp} \leq 4$, which means that the level geomagnetic activity was relatively quiet. Only for the day of the earthquake between 00:00-03:00 UT, Kp $=5$ which according to the National Oceanic and Atmospheric Administration (NOAA) space weather scales actually points to a minor storm.

The F10.7 index is an indicator of the solar conditions. Data for this index were downloaded from the OMNI database

(https://omniweb.gsfc.nasa.gov/form/dx1.html). In Figure 2 it can be seen that F10.7 for the period under study was quite stable, which points to low solar activity.

\subsection{THE STATISTICAL METHOD}

In order to look for ionospheric disturbances before the day of the earthquake, a well established and used statistical method was applied (e.g. Liu et al., 2004; Zhou et al., 2009; Zhu et al., 2010; Yao et al., 2012; Zhu et al., 2013; Alcay, 2016; SotomayorBeltran, 2019). Assuming that the cells in the grid of the GIMs, for a particular timestamp (e.g., $t s=00 \mathrm{UT}$ ), have a normal distribution within a period of days, a sliding window to the VTEC data over the location of the Acari earthquake was applied. This window started some days before the event and went until a few days after the earthquake. For each period of days within the window, the mean $(\mu)$ and standard deviation $(\sigma)$ values for each timestamp (i.e., $t s=$ 00 UT, 02 UT, 04 UT, etc.) were calculated.

To establish when there is an ionospheric anomaly, the upper and lower bounds ( $U B$ and $L B$, respectively) were defined as follows:

$U B=\mu+2 \sigma$

$L B=\mu-2 \sigma$

If a VTEC value for a certain geographic location at a particular time falls above the upper bound or bellow the lower bound, there is a positive or a negative ionospheric anomaly detection with a $95 \%$ confidence level, respectively.

\section{RESULTS AND DISCUSSION}

Observing at the VTEC time series over the location of the seismic event (Fig. 3), ionospheric anomalies are hardly identified. However for January 1 and 2, 2018 between $\sim$ 18:00-23:00 UT and $\sim$ 13:00-20:00 UT, respectively, the VTEC values are similar to the ones from the upper bound. In order to have a broader and better view if in these days there are any ionospheric disturbances, the sliding window method was applied to each cell in the geographical grid. The final result was a $3 \mathrm{D}$ cube made up of twodimensional differential VTEC ( $\Delta$ VTEC) maps. The $\triangle \mathrm{VTEC}$ is equal to 0 when the VTEC value for a given time at a certain day falls within the $U B$ and 


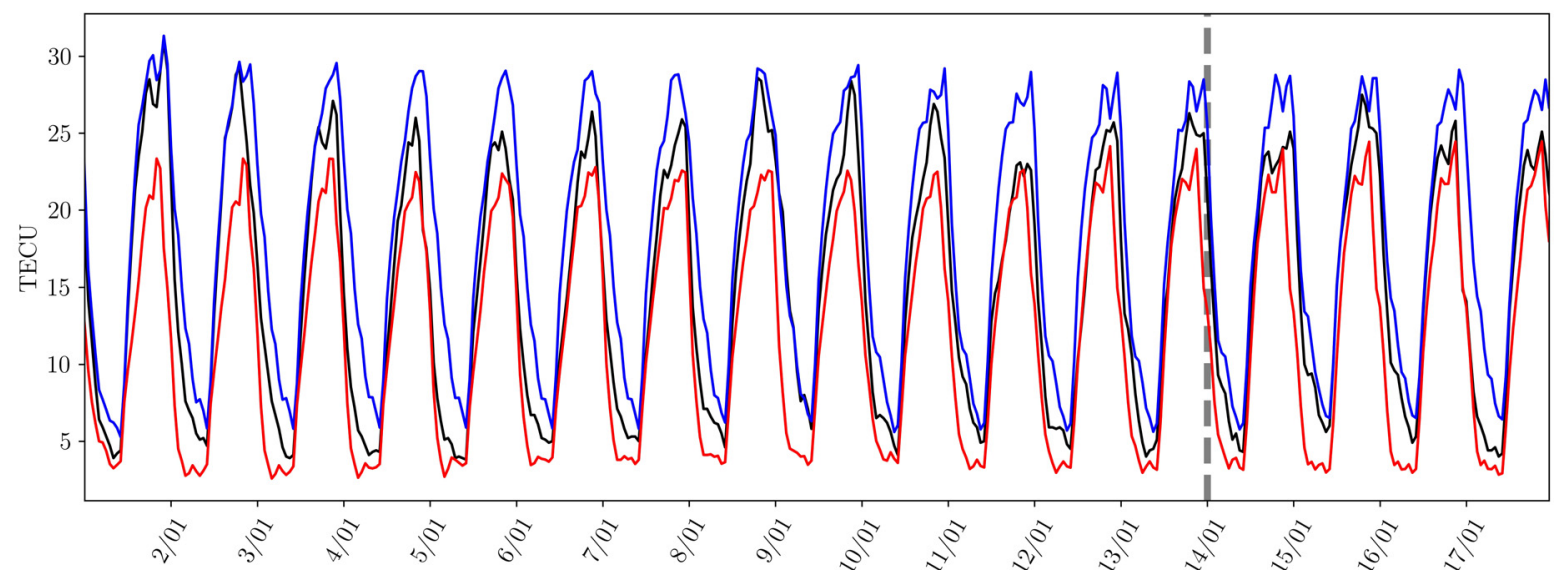

Fig. 3 The black line shows the VTEC time series over the geographic location of the epicenter $\left(15.77^{\circ} \mathrm{S}\right.$ and $74.71^{\circ} \mathrm{W}$ ) of the Acari earthquake for the period between January 1 and 18, 2018. The blue and red lines indicate the upper and lower bound, respectively. The dashed vertical grey line indicates the day the seismic event happened.

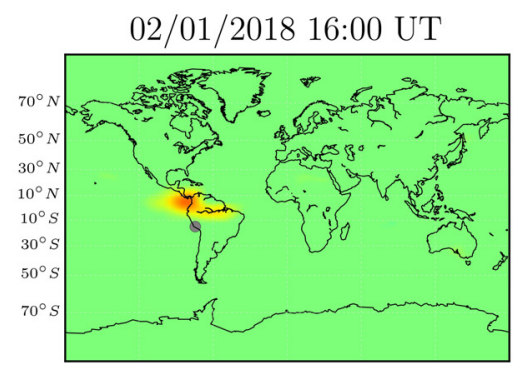

02/01/2018 20:00 UT

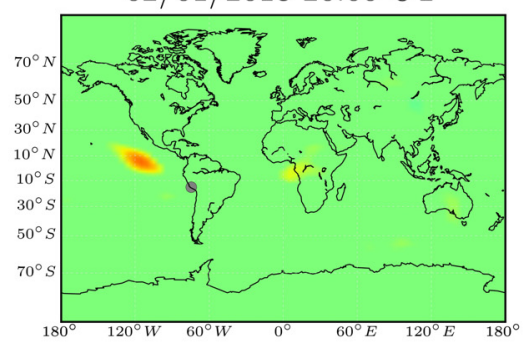

02/01/2018 18:00 UT

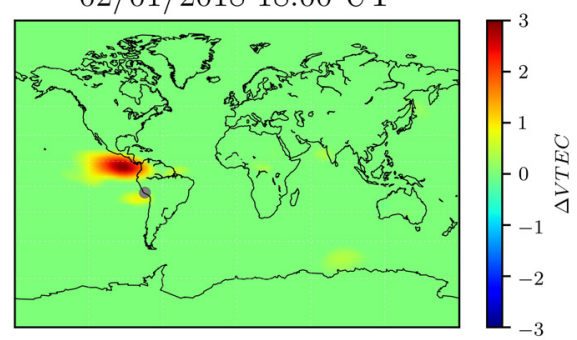

16/01/2018 20:00 UT

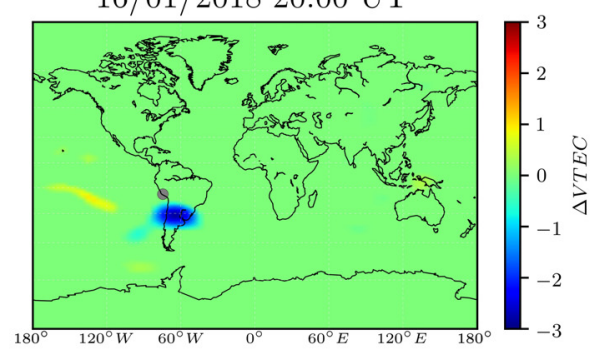

Fig. 4 Global ionospheric anomaly maps for days (January 2 and 16, 2018) in which positive and negative disturbances are observed. The grey circles in all the maps point to the location of the earthquake's epicenter.

$L B$. The $\triangle$ VTEC are positive and negative when the VTEC value for a given time at a certain day falls above or bellow the $U B$ and $L B$, respectively.

\subsection{IONOSPHERIC DISTURBANCE PRIOR TO THE EARTHQUAKE}

After carefully inspecting the $\triangle$ VTEC cube, it was observed that for January 1, 2018 at $\sim$ 18:0023:00 UT there was not a clear detection of an ionospheric disturbance. However, on January 2 (12 days before the seismic event) a positive ionospheric anomaly is clearly identified. This disturbance appears approximately at 16:00 UT in the northern hemisphere at $\sim 5^{\circ} \mathrm{N}$ (Fig. 4) and has its strongest intensity at around 18:00 UT, time when another positive anomaly in the magnetic conjugated region in the southern hemisphere $\left(\sim 18^{\circ} \mathrm{S}\right)$ is also identified. This agrees well with other observations of seismoionospheric signatures observed a few days before an earthquake (e.g., Zhu et al., 2010; Yao et al., 2012; Zhu et al., 2013; Li et al., 2015). The maximum $\Delta$ VTEC at 18:00 UT is 2.94 TECU. Afterwards, at 20:00 UT it can be seen that the anomaly moved westwards until it faded away. From Figure 2 it can be seen that on January 2 the geomagnetic indices are Dst $<-20 \mathrm{nT}$ and $\mathrm{Kp} \leq 2$, which point to fairly quiet geomagnetic conditions.

The town of Acari is located at low latitudes, which means that the EIA passes right above it. This phenomenon consists of two regions of enhanced plasma density located approximately $15^{\circ}$ north and south of the magnetic dip equator (McDonald et al., 2011), and are product of the equatorial fountain effect (Appleton, 1946). Pulinets and Legen'ka (2002) 


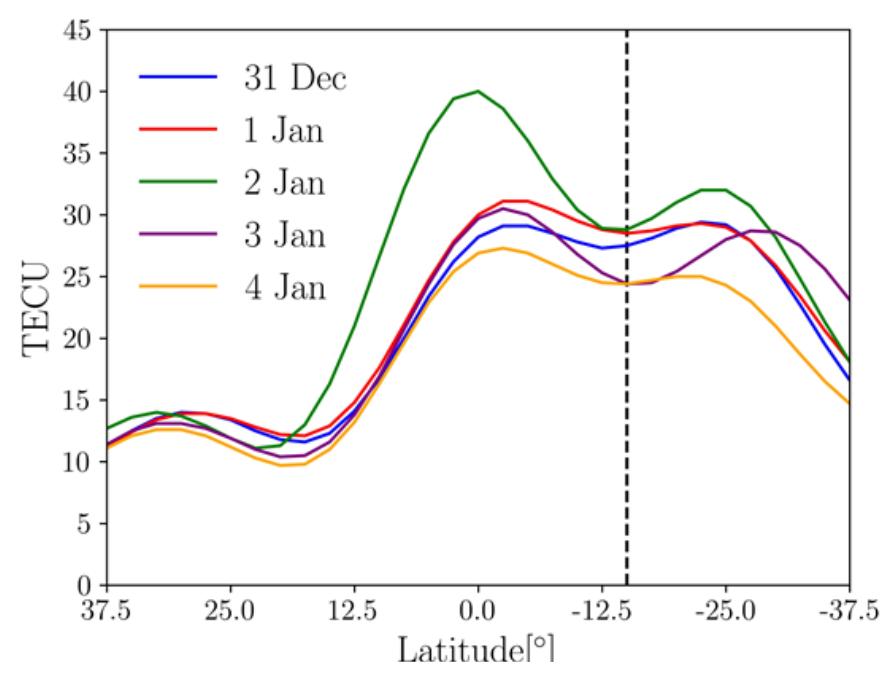

Fig. 5 Structure of the VTEC for the $75^{\circ} \mathrm{W}$ meridian at 18:00 UT starting on December 31, 2017 until January 4 , 2018. A relevant range of latitudes is shown, $37.5^{\circ} \mathrm{N}-37.5^{\circ} \mathrm{S}$. The vertical dashed black line indicates the latitude $\left(15.77^{\circ} \mathrm{S}\right)$ where the earthquake took place.

and Pulinets (2012) have indicated that some days prior to a seismic event, the shape of the equatorial anomaly is modified. These modifications are divided in three groups: enlargement of the EIA, disappearance of the crests and EIA distortions through changes in the locations of the trough and the crests. Taking the VTEC values along the constant longitude of $75^{\circ} \mathrm{W}$ (approximately above the earthquake's epicenter) for the different hours of the day, it was found out that at 18:00 UT (11:00 LT) the shape of the EIA considerably changed the most. In Figure 5 the VTEC shape for the longitude of $75^{\circ} \mathrm{W}$ at 18:00 UT is shown between December 31, 2017 and January 4, 2018. It can be clearly seen that the EIA remains rather stable between December 31, 2017 and January 1, 2018; however, on January 2 the EIA changes significantly its shape through the considerable amplification of its northern and southern crests. The increase of the northern crest was of $33.3 \%$ ( 10 TECU) relative to a stable day. This situation is rather similar to what Zakharenkova et al. (2006) described what happened days before the earthquake in Indonesia on December 26, 2004. Two days before this event, they also reported the amplification of the EIA during daytime. After January 2, 2018, as shown in Figure 5, for January 3 and 4, 2018 the EIA shows its normal variability under stable conditions.

As considered by Pulinets (2009) and Pulinets (2012), ionization of the air produced by natural ground radioactivity can be the main driving force for the observed enhancement of electron density 12 days prior to the seismic event. Due to active tectonic faults, radon is emanated from the Earth's crust, which will produce air ionization. If the ionization levels are high, heavy ions will abound in the boundary of the atmosphere, which will lead to a decrease of air conductivity. This decrement will cause an increase of the ionospheric potential with respect to the ground and thus a positive ionospheric anomaly will arise.

\subsection{IONOSPHERIC DISTURBANCE AFTER THE EARTHQUAKE}

On January 16 (2 days after the earthquake), a negative ionospheric disturbance was detected. Figure 4 shows this disturbance occurring to the south $\left(\sim-30^{\circ} \mathrm{S}\right)$ of the seismic event. The minimum $\Delta$ VTEC of this disturbance on January 16 at 18:00 UT is - 2.83 TECU. Zou (2010) and Xinzhi et al. (2014) have also reported negative anomalies 2 and 8 days after seismic events, respectively; however, no physical mechanism was put forward to account for these. For the Acari earthquake like in the aforementioned studies, the geomagnetic conditions (Fig. 2) also remained rather quiet after the event. Thus, it can only be suggested that the observed negative anomaly could be product of post-earthquake activity.

\section{CONCLUSIONS}

Using IONEX files from CODE, ionospheric anomalies before and after the catastrophic seismic event that took place near the town of Acari, Peru, on January 14, 2018 were identified. By creating twodimensional differential VTEC maps, a positive ionospheric disturbance was observed 12 days (January 2) before the incident in the northern hemisphere. During this day the geomagnetic conditions, based on geomagnetic indices observations, and solar ones remained relatively stable. Additionally, due to the low-latitude location of the Acari earthquake, the meridian VTEC shape where the earthquake took place was analyzed. It was finally revealed that for January 2, 2018 the EIA shape changed through an amplification of its northern and southern crests; the northern one showing the strongest variation (33.3\% VTEC increment). Furthermore, it is suggested that air ionization due to the earthquake's preparation is increasing the electron density in the EIA. Under all the aforementioned considerations, the positive ionospheric disturbance is hence suggested to be 
a precursor of the seismic event. Finally, 2 days after the earthquake, a negative ionospheric anomaly was also observed. However in this case, it can only be hinted at that this anomaly is associated to the earthquake due to the quiet geomagnetic and solar conditions, as not well-know mechanism can still account for what happens in the ionosphere a few days after an earthquake occurs.

\section{REFERENCES}

Akhoondzadeh, M., De Santis, A., Marchetti, D., et al.: 2018, Multi precursors analysis associated with the powerful Ecuador $(\mathrm{Mw}=7.8)$ earthquake of 16 April 2016 using swarm satellites data in conjunction with other multi-platform satellite and ground data. Adv. Space Res., 61, 248-263.

DOI: $10.1016 /$ j.asr.2017.07.014

Alcay, S.: 2016, Analysis of ionospheric TEC variations response to the $\mathrm{Mw} 7.2 \mathrm{VAN}$-earthquake. Acta Geodyn. Geomater., 13, 257-262. DOI: 10.13168/AGG.2016.0007

Afraimovich, E.L., Astafyeva, E.I., Demyanov, V.V., et al.: 2013, A review of GPS/GLONASS studies of the ionospheric response to natural and anthropogenic processes and phenomena. J. Space Weather Clim., 3, A27. DOI: $10.1051 / \mathrm{swsc} / 2013049$

Appleton, E.V.:1946, Two anomalies in the Ionosphere. Nature, 157, 691. DOI: 10.1038/157691a0

Buonsanto, M.: 1999. Ionospheric storms - A review. Space Sci. Rev., 88, 563-601. DOI: $10.1023 / \mathrm{A}: 1005107532631$

Coster, A. and Komjathy, A.: 2008, Space weather and the global positioning system. Space Weather, 6, S06D04. DOI: $10.1029 / 2008$ SW000400

Danilov, A.D.: 2013. Ionospheric F-region response to geomagnetic disturbances. Adv. Space Res., 52, 343366. DOI: 10.1016/j.asr.2013.04.019

Guo, J., Li, W., Yu, H., et al.: 2015. Impending ionospheric anomaly preceding the Iquique $\mathrm{Mw} 8.2$ earthquake in Chile on 2014 April 1. Geophys. J. Int., 203, 14611470. DOI: $10.1093 /$ gji/ggv376

Hernández-Pajares, M., Juan, J.M., Sanz, J., et al.: 2009. The IGS VTEC maps: a reliable source of ionospheric information since 1998. J. Geodesy, 83, 263-275. DOI: $10.1007 / \mathrm{s} 00190-008-0266-1$

Li, J., You, X., Zhang, R., et al.: 2015, Ionospheric total electron content disturbance associated with May 12, 2008, Wenchuan earthquake. Geodesy and Geodynamics, 6, 2, 126-134. DOI: 10.1016/j.geog.2015.01.003

Liu, J.Y., Chuo, Y.J., Shan, S.J., et al.: 2004, Pre-earthquake ionospheric anomalies registered by continuous GPS TEC measurements. Ann. Geophys. 22, 1585-1593. DOI: 10.5194/angeo-22-1585-2004

McDonald, S.E., Coker, C., Dymond, K. F., et al.: 2011, A study of the strong linear relationship between the equatorial ionization anomaly and the prereversal $\mathrm{E} \mathrm{X}$ B drift velocity at solar minimum. Radio Sci., 46, 1-9. DOI: $10.1029 / 2011$ RS004702

Mubarak, W.A., Abdullah, M. and Misran, N.: 2009, Ionospheric TEC response over Simeulue earthquake of 28 March 2005. 2009 International Conference on Space Science and Communication, 175-178. DOI: 10.1109/ICONSPACE.2009.5352643

Pulinets, S.A.: 2012, Low-latitude atmosphere-ionosphere effects initiated by strong earthquakes preparation process. Int. J. Geophys., 2012, ID 131842. DOI: $10.1155 / 2012 / 131842$

Pulinets, S.A.: 2009, Physical mechanism of the vertical electric field generation over active tectonic faults. Adv. Space Res., 44, 767-773. DOI: $10.1016 /$ j.asr.2009.04.038

Pulinets, S. A. and Legen'ka, A.D.: 2002, Dynamics of the near-equatorial ionosphere prior to strong earthquakes. Geomagn. Aeronomy, 42, 227-232.

Pundhir, D., Singh, B., Singh, O.P., et al.: 2015, Study of ionospheric precursors related to an earthquake $(\mathrm{M}=7.8)$ of 16 April, 2013 using GPS-TEC measurements: Case study. J. Geogr. Nat. Disasters, 5, 1-3. DOI: $10.4172 / 2167-0587.1000137$

Schaer, S., Gurtner, W. and Feltens, J.: 1998, IONEX: The ionosphere map exchange format version 1, 233-247.

Sharma, G., Champatiray, P. K., Mohanty, S., et al.: 2017, Ionospheric TEC modelling for earthquakes precursors from GNSS data. Quatern. Int., 462, 65-74. DOI: 10.1016/j.quaint.2017.05.007

Sotomayor-Beltran, C.: 2019, Ionospheric anomalies preceding the low-latitude earthquake that occurred on April 16, 2016 in Ecuador. J. Atmos. Sol.Terr. Phys., 182, 61-66. DOI: 10.1016/j.jastp.2018.11.003

Xinzhi, W., Junhui, J., Dongjie, Y., et al.: 2014, Analysis of ionospheric VTEC disturbances before and after the Yutian Ms 7.3 earthquake in the Xinjiang Uygur Autonomous Region. Geodesy and Geodynamics, 5, 8-13. DOI: 10.3724/SP.J.1246.2014.03008

Yao, Y.B., Chen, P., Wu, H., et al.: 2012, Analysis of ionospheric anomalies before the $2011 \mathrm{Mw} 9.0$ Japan earthquake. Chin. Sci. Bull., 57, 500-510. DOI: $10.1007 / \mathrm{s} 11434-011-4851-y$

Zakharenkova, I.E., Shagimuratov, I.I., Tepenitzina, N.Y., et al.: 2008, Anomalous modification of the ionospheric total electron content prior to the 26 September 2005 Peru earthquake. J. Atmos. Sol.Terr. Phys., 70, 19191928. DOI: $10.1016 /$ j.jastp.2008.06.003

Zakharenkova, I.E., Krankowski, A. and Shagimuratov, I.I.: 2006, Modification of the low-latitude ionosphere before the 26 December 2004 Indonesian earthquake. Nat. Hazard. Earth Sys. Sci., 6, 817-823. DOI: 10.5194/nhess-6-817-2006

Zhou, Y., Wu, Y., Qiao, X., et al.: 2009, Ionospheric anomalies detected by ground-based GPS before the Mw 7.9 Wenchuan earthquake of May 12, 2008. China. J. Atmos. Sol.Terr. Phys., 71, 959-966. DOI: 10.1016/j.jastp.2009.03.024

Zhu, F., Zhou, Y. and Wu, Y.: 2013, Anomalous variation in GPS TEC prior to the 11 April 2012 Sumatra earthquake. Astrophys. Space Sci., 345, 231-237. DOI: 10.1007/s10509-013-1389-2

Zhu, F., Wu, Y., Lin, J., et al.: 2010, Temporal and spatial characteristics of VTEC anomalies before Wenchuan Ms 8.0 earthquake. Geodesy and Geodynamics, 1, 2328. DOI: $10.3724 /$ SP.J.1246.2010.00023

Zou, Y.: 2010, Ionospheric anomalies detected by GPS TEC measurements during two strong earthquakes in Indonesia. 2nd Conference on Environmental Science and Information Application Technology, 199-202. DOI: 10.1109/ESIAT.2010.5567309

Zou, Y. and Zhao, T.: 2010, Ionospheric anomalies detected by GPS TEC measurements during the 15 August 2007 Peru earthquake. International Conference on Microwave and Millimeter Wave Technology, 12161219. DOI: 10.1109/ICMMT.2010.5525006 